\title{
Septal Sealing in the Basidiomycete Coriolus versicolor
}

\author{
By R. C. AYLMORE, "G. E. WAKLEY AND N. K. TODD \\ Department of Biological Sciences, Washington Singer Laboratories, University of Exeter, \\ Perry Road, Exeter EX4 4QG, UK
}

(Received 21 May 1984)

The way in which the dolipore apparatus contains hyphal damage, and the process of septal sealing have been studied in Coriolus versicolor using combined light and electron microscopy. The technique used allows the structure of septa in adjacent damaged and undamaged hyphae to be compared. The results show that septal sealing, following damage, is a two stage process. The first is the instantaneous plugging of the pore channel with electron-dense material. The second, beginning several minutes later, involves the detachment of the septal apparatus present in the ruptured compartment and a re-modelling of the septal swelling on the other side of the wall to give a permanent seal. The parenthesomes play no part in the plugging response.

\section{INTRODUCTION}

Buller (1933) recognized that the septal pores of higher fungi (deuteromycotina, ascomycotina and basidiomycotina), whilst open during active translocation and growth, could become sealed in the event of injury to the mycelium. In this way, it was argued, damage to hyphae was localized and loss of cytoplasm confined to single compartments. It is now accepted that this may constitute one of the principal functions of fungal septa. It is likely that septal sealing also plays an important role in colony development and differentiation (Gull, 1978).

In ascomycetous fungi there appear to be two mechanisms by which their simple septal pores can be plugged. As a rule this involves occlusion by round or oval shaped electron-dense structures, the so-called Woronin bodies. Between 3 and 12 of these membrane-bound organelles become associated with the septum and lodged in the pore when the adjacent compartment is damaged (Reichle \& Alexander, 1965; Brenner \& Carroll, 1968; Furtado, 1971 ; McKeen, 1971; Wergin, 1973). In other instances, however, occlusion appears to result from deposition of electron-dense material in the region of the pore, often in association with various projecting structures arising from the pore rim (see Shatkin \& Tatum, 1959; Lowry \& Sussman, 1966; Bourne, 1968; Brenner \& Carroll, 1968; Trinci \& Collinge, 1973; Brouchart \& Demoulin, 1975; Collinge et al., 1978). Most basidiomycete fungi, on the other hand, which possess an elaborate and highly differentiated septal apparatus, the dolipore (for review see Bracker, 1967; Gull, 1978), apparently lack structures akin to Woronin bodies. However, there is evidence from many studies which suggests that the dolipore channel can become completely or partially plugged by electron-dense material (Bracker \& Butler, 1963; Koltin \& Flexer, 1969; Casselton et al., 1971 ; Moore \& Marchant, 1972; Setliff et al., 1972; Craig et al., 1977). These investigations did not use an experimental system which allowed precise specimen selection, and consequently it was not possible to undertake accurate time-course studies of the plugging reaction, or to establish details concerning the origin, position or stimulus causing occlusion of a given septum. Here we show, using combined light and electron microscopy, the way in which the dolipore apparatus responds to hyphal damage and describe the mechanism of septal sealing in Coriolus versicolor (L. ex Fr.) Quél. 


\section{METHODS}

Sirains and culrure conditions. Both dikaryotic and monokaryotic cultures of Coriolus versicolor were used. The strains were isolated from the wild. Mycelia were grown at $25^{\circ} \mathrm{C}$ as monolayers on cellophane membranes overlaying 10\%(v/v) glucose minimal medium (Casselton \& Casselton, 1966) solidified with $1.5 \%(w / v)$ agar. Media and cellophane membranes were sterilized by autoclaving at $10 \mathrm{lbf} \mathrm{in}^{-2}(69 \mathrm{kPa})$ for $20 \mathrm{~min}$.

Hyphal damage. A piece of cellophane $\left(10 \mathrm{~mm}^{2}\right)$ carrying a small area of mycelial monolayer was cut from the periphery of an actively growing culture. This was placed on a microscope slide coated with growth medium and covered with a coverslip. After overnight incubation, the coverslip was carefully removed and the larger leading hyphae of the regenerating colony were located. After a $10 \mathrm{~min}$ recovery period, damage was inflicted to individual hyphal compartments. These were selected under a dissecting microscope and punctured using a finely sharpened tungsten needle.

Light microscopy. After damage, the membrane carrying the mycelium was rapidly transferred to a microculture chamber. Full details of the chamber and its preparation have been described elsewhere (Aylmore \& Todd, 1984). The damaged hyphae were located and examined under phase-contrast optics. A Leitz Dialux microscope was used and all photographs were taken using Kodak Technical Pan 2415 film.

Electron microscopy. Membranes were transferred to fixative at $30 \mathrm{~s}$ and various times up to $30 \mathrm{~min}$ after damage. For longer periods before fixation, namely 1,2 and $4 \mathrm{~h}$, the coverslips were replaced and the slides incubated at $25^{\circ} \mathrm{C}$. After processing and flat-embedding, the damaged compartments were located, the positions of the septa recorded, and the selected hyphae sectioned longitudinally (for details see Aylmore, 1983; Aylmore \& Todd, 1984). Sections were stained for $4 \mathrm{~min}$ in lead citrate (Reynolds, 1963) and examined at 60-80 kV with a JEM 100S electron microscope. Septa present in damaged hyphae were examined and compared to those found in undamaged regions of the same mycelium. These latter septa were used as controls.

\section{RESULTS}

The septa of both dikaryotic and monokaryotic hyphae showed the same response to damage and consequently, for ease of description, they will be considered together. Our findings are based on at least 20 separate sets of observations on the two types of hyphae.

\section{Light microscopy}

Fig. I shows the sequence of events following puncture of the apical compartment of a leading hypha. This resulted in the rapid loss of cytoplasm and bulging of the septa towards the affected compartment. The plugging reaction appeared to be virtually instantaneous as there was no evidence of leakage of cytoplasm into the damaged region. After $15 \mathrm{~min}$, an opaque hemispherical pad-like structure formed in the centre of the concave surface of the bulging cross-wall (Fig. $1 \mathrm{a}$ ). These remained visible for the whole time that the damaged hyphae were observed, at least $24 \mathrm{~h}$. Normal forward-facing lateral branches emerged after about $75 \mathrm{~min}$ from a position directly behind the plugged septa (Fig. $1 b$ ). These showed extended growth and typical patterns of mitosis and septation (Fig. Ic). Rarely, intrahyphal hyphae emerged through the plugged cross-wall.

Inspection of septa further back along the hyphae showed them to be normal. They did not appear to bulge or develop refractive pads; rather, the dolipore apparatus, when visible under phase-contrast remained intact. Immature septa, on the other hand, were unable to contain damage, which subsequently spread until the first fully developed dolipore was encountered. When intercalary compartments were punctured, the delimiting septa behaved as above, bulging in towards the damaged region.

\section{Electron microscopy}

The septa of undamaged leading hyphae possessed the typical dolipore structure (Fig. 2a). The pore channels of the first five septa back from the apex in these hyphae were generally unoccluded. In contrast, septa delimiting damaged apical compartments were not typical and showed a response which followed a consistent train of events. In hyphae fixed within $30 \mathrm{~s}$, discrete electron-dense plugs, not bounded by membrane, completely occluded either end of the pore channel leaving the central region clear (Fig. $2 b$ ). Occasionally only a single plug formed; this was invariably positioned in the basal end of the pore. During this initial reaction very little cytoplasm was extruded into the disrupted compartment. At this stage the septal swellings and parenthesomes remained intact. In the following $10 \mathrm{~min}$, most of the pore channel became full of 

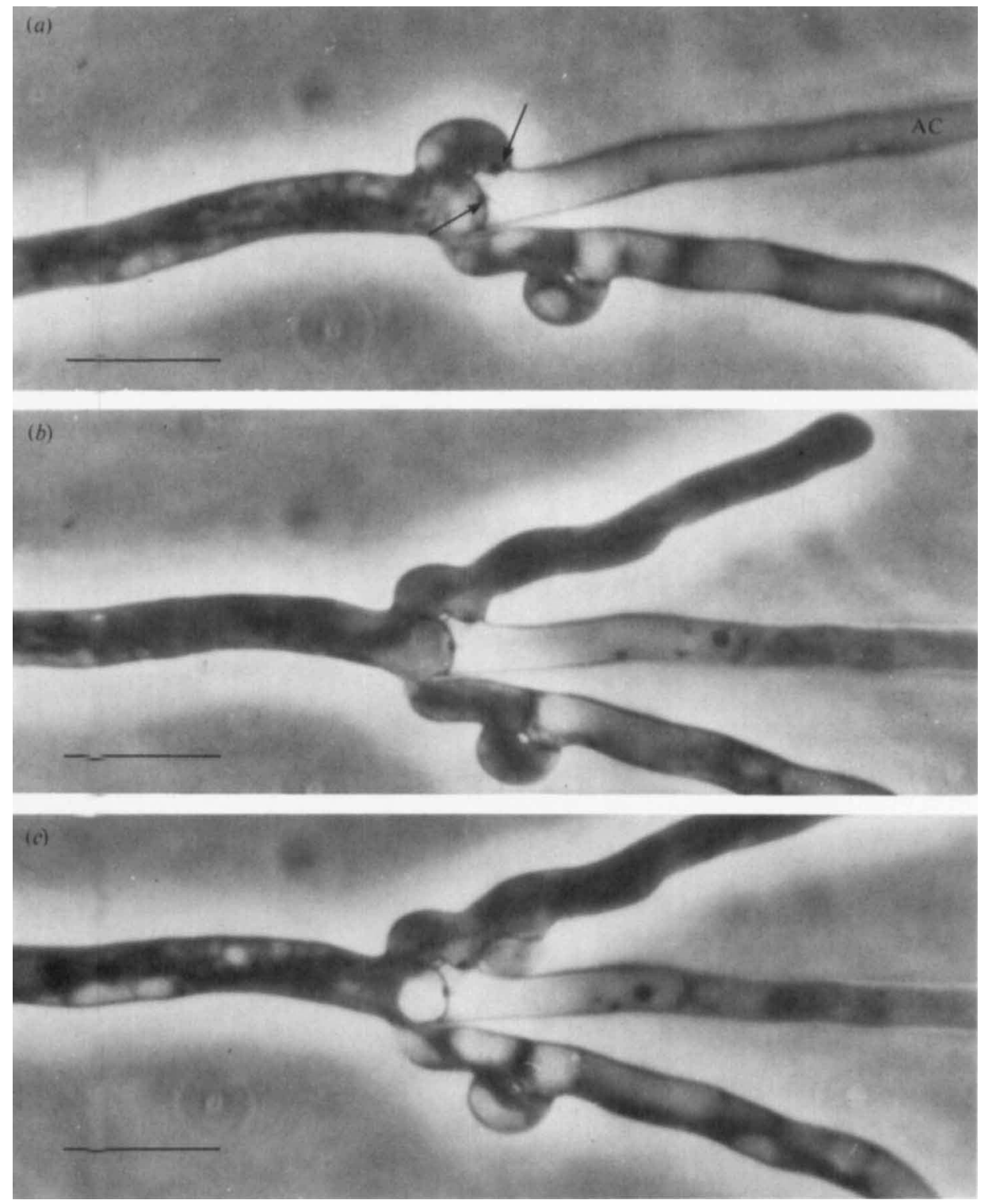

Fig. 1. Photomicrographs showing septa of a leading dikaryotic hypha after puncture of the apical compartment (AC). (a) 20 min after puncture, note the opaque pads on the concave surface of both bulging cross-walls (arrowed); (b) $110 \mathrm{~min}$ after damage, a forward-facing lateral branch has emerged from just behind the plugged septa; (c) 150 min after damage, showing clamp formation at the base of the branch. Opaque structures remain visible at the centre of the sealed septa. Bars, $10 \mu \mathrm{m}$.

electron-opaque material, this being accompanied by a progressive cleavage, away from the cross-wall, of the septal swelling present in the empty damaged cell (Fig. $3 a, b$ ). On completion of this process, the whole septal apparatus, with parenthesome still attached, split away (Fig. $3 c$ ). At the same time, in the penultimate cell, a hemispherical pad, derived from deformation of the septal swellings, was laid down around the sealed pore (Fig. 3d,e). The material comprising this structure showed similar staining properties to the rest of the cross-wall. During the earlier stages of this process the parenthesome remained intact and attached to the cross-wall (Fig. $3 \mathrm{c}$ ). 

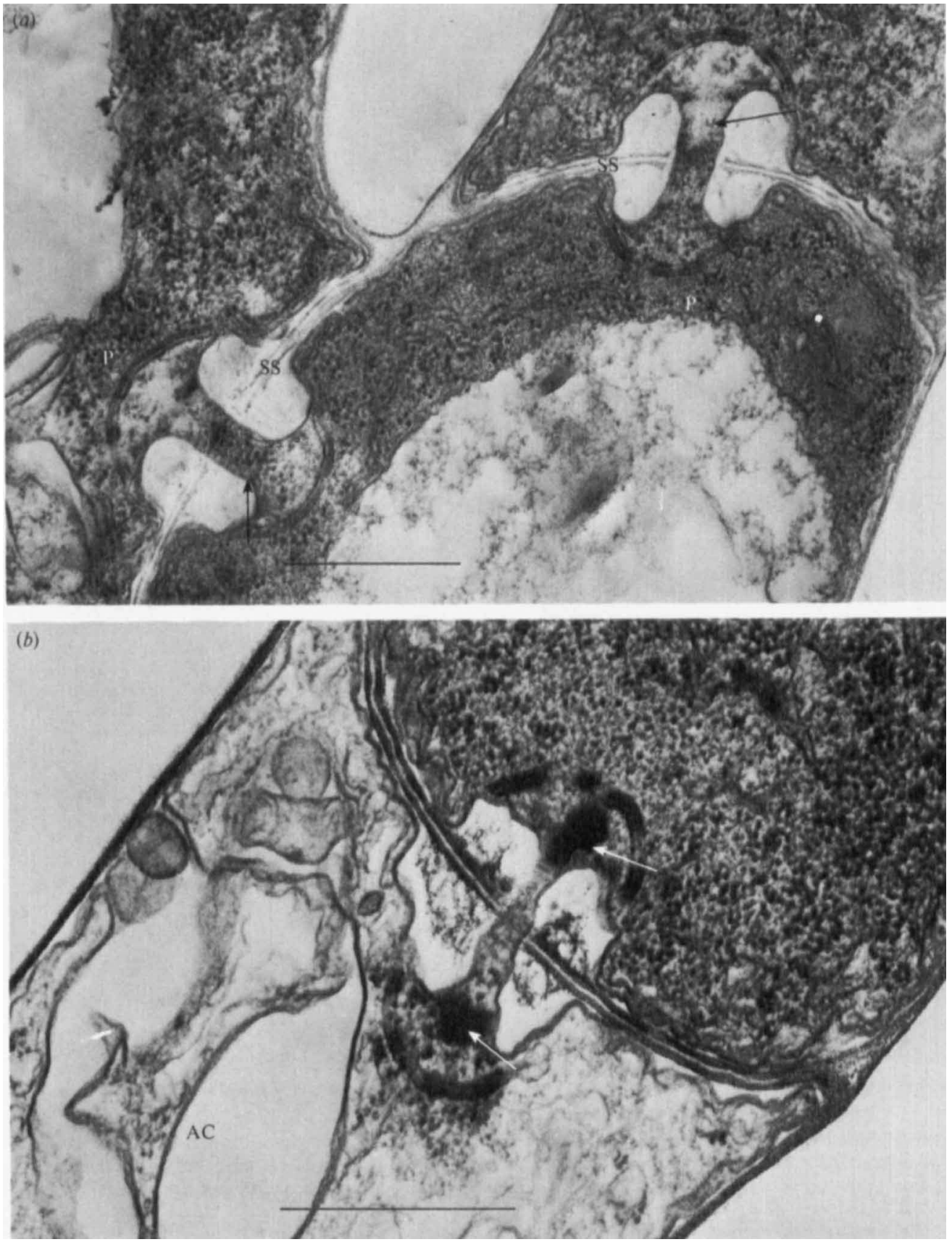

Fig. 2. (a) Median section through the apical clamp connection of an undamaged leading dikaryotic hypha. Longitudinal striations are present in the unobstructed pore channels (arrowed). Note the typical appearance of the septal swellings (SS) and parenthesomes (P). (b) Median section of a leading monokaryotic hypha fixed within 30 s of puncturing the apical compartment (AC), showing the initial plugging response. The septal apparatus remains intact. Discrete plugs of amorphous electron-dense material (arrowed) obstruct either end of the pore channel leaving the central region clear. Little cyto. plasm escapes into the disrupted cell. Bars, $0.5 \mu \mathrm{m}$. 
Specimens fixed between $30 \mathrm{~min}$ and $4 \mathrm{~h}$ after damage showed little further development. Remnants of the septal apparatus disappeared from the injured compartment, although fragments of parenthesome sometimes persisted and were evident for up to $1 \mathrm{~h}$ (Fig. $3 \mathrm{f}$ ). Likewise, the parenthesome on the other side of the wall eventually detached (Fig. $3 g$ ) and fragmented.

Examination of the second and third septa back from the damaged region, fixed within $15 \mathrm{~min}$, showed a form of plugging reaction, although this was somewhat weaker than the one described above. Even in the cross-walls present at the base of lateral branches arising at these points, obstruction of the pore channel was evident. In such instances, the reaction took the form of densely staining bands across both entrances of the pore channel (Fig. 4). Occasionally these structures were restricted to the basal facing side of the pore. In specimens fixed after $1 \mathrm{~h}$ these structures appeared as hollow rings positioned in the mouth of the dolipore, whereas after 2-3 h occlusions were generally absent and such dolipores appeared normal.

\section{DISCUSSION}

The work reported here is the first demonstration of the complete mechanism of septal sealing in a basidiomycete fungus. It suggests that the response to damage is a two stage process. The first stage involves the rapid formation of electron-dense pore plugs, similar in structure to those described by other workers (Moore \& McAlear, 1962; Bracker \& Butler, 1963; Koltin \& Flexer, 1969; Casselton et al., 1971; Moore \& Marchant, 1972; Setliff et al., 1972; Craig et al., 1977). These serve to prevent extensive loss of cytoplasm. The septal swellings and parenthesomes apparently play no part in these initial events. The second stage begins within 5 min of damage being inflicted and entails detachment and eventual degeneration of the septal apparatus present in the ruptured compartment. Meanwhile, on the other side of the cross-wall the septal swelling becomes re-modelled around, and often over, the pore plug to give a more permanent seal. The structures resulting from this process have been reported elsewhere in situations involving senescence of hyphal compartments (Bracker \& Butler, 1963; Wells, 1964). The whole process is complete within $20 \mathrm{~min}$ and no further modification was found within $\mathbf{4 h}$. These observations lend support to the view that septal swellings may be labile in nature, having different chemical and physical properties to the rest of the cross-wall, and that parenthesomes are composed of rigid material which is not directly involved in the occlusion reaction (for discussion see Bracker \& Butler, 1963, 1964; Wells, 1964; Bracker, 1967; Moore \& Marchant, 1972; Wessels \& Sietsma, 1979).

In septa not in direct contact with the damaged compartment, only the first stage of the sealing process occurs, and patterns observed in $1-3 \mathrm{~h}$ specimens would suggest that this often less intense reaction is reversible. Indeed, the torus of electron-opaque material of ten found at the mouth of the pore channel and interpreted as a plugging precursor (Setliff et al., 1972) may in fact represent pore plugs in the process of dissolution.

The mechanism responsible for the rapid sealing of dolipores is still obscure. The plugs appear to be formed in situ, occlusion occurring almost instantaneously. In open dolipores, longitudinal striations traverse the channel (Fig. 2a); these probably reflect the presence of microfilaments (Moore \& Marchant, 1972). Perhaps these structures, or some other component of the cytoplasm, simply coagulate as a result of the sudden increase in hydrostatic pressure occurring in the pore channel when turgor is lost in the adjacent compartment. It may be significant that the less intense plugging reaction found in more remotely positioned septa often appears as transverse bands within the microfilament bundle (Fig. 4). The mechanism in basidiomycetes has little in common with the rapid plugging in ascomyceteous fungi which involves pre-formed membrane-bound organelles. Superficially it resembles more the deposition mechanism reported for the simple pores in these organisms (see Shatkin \& Tatum, 1959; Lowry \& Sussman, 1966; Bourne, 1968; Brenner \& Carroll, 1968; Trinci \& Collinge, 1973; Collinge et al., 1978), although this appears to be a much slower response since the various stages of the process can be so readily observed. 

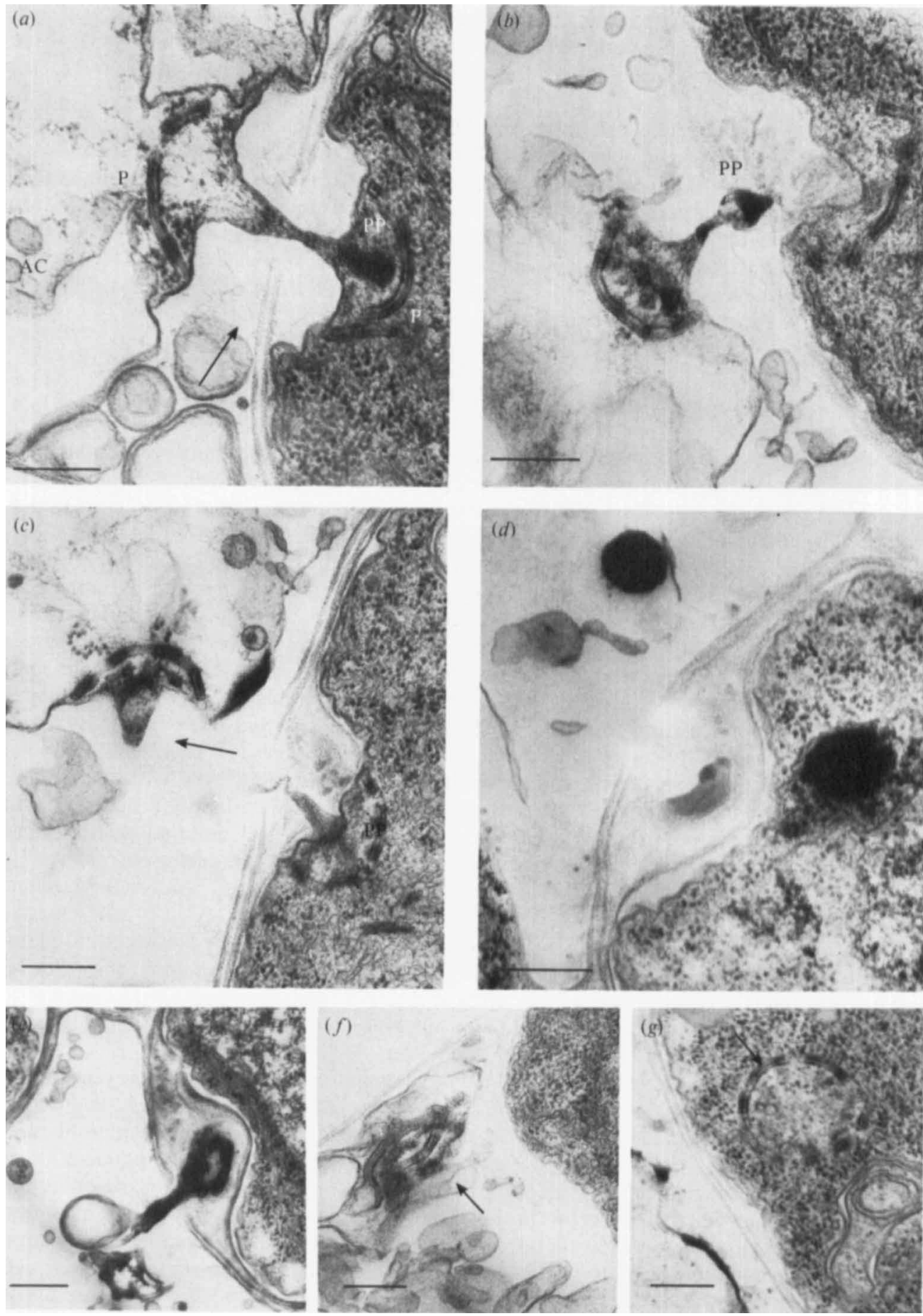

Fig. 3. Transmission electron micrographs showing the second stage of the plugging response. The punctured apical compartment (AC) is on the left in each case. (a) After $5 \mathrm{~min}$ the plasmalemma in the damaged compartment peels away to expose the septal swelling (arrowed). Note the single pore plug (PP), intact parenthesomes (P) and electron-dense material filling the pore channel. $(b, c)$ Within 20 min the exposed septal swellings degenerate. Eventually the septal apparatus with attached 


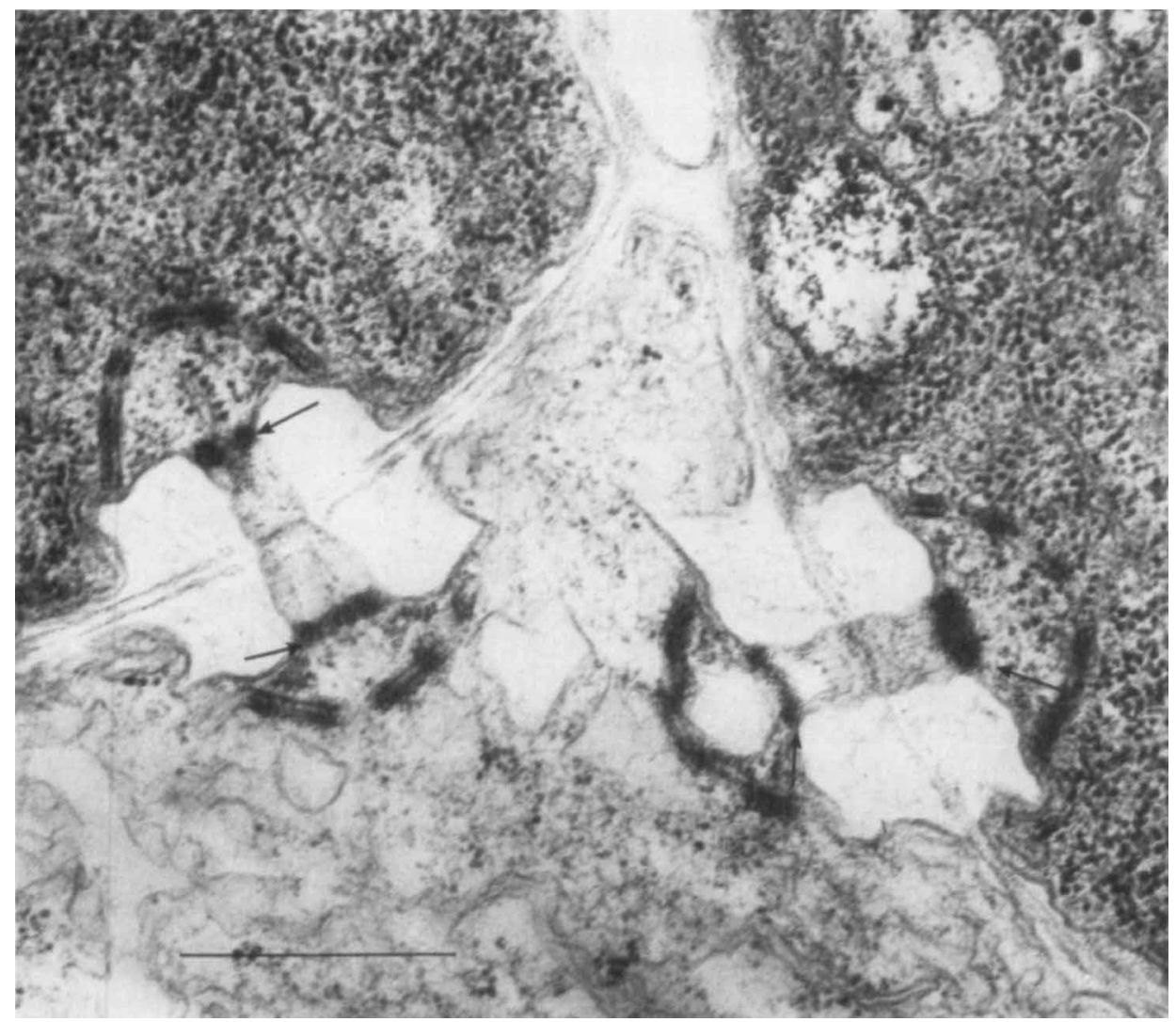

Fig. 4. Transmission electron micrograph showing a median section through the second septum behind the punctured apical compartment, fixed within $5 \mathrm{~min}$ of damage. A weak plugging reaction occurs in an otherwise typical dolipore. Bands of electron-dense material (arrowed) occlude both ends of the pore channel. Bar, $0.5 \mu \mathrm{m}$.

Understanding the function of septa provides the key to the cell concept in the higher fungi. Clearly, as in ascomycetous species, the septa of basidiomycetes are highly efficient at localizing the effects of damage to single hyphal compartments. However, the mechanism operating in the case of dolipores shows little similarity to that found in cross-walls possessing simple pores. It is likely that the mechanism of septal sealing described here for $C$. versicolor is applicable generally to basidiomycetes. We have already carried out observations of this process in Schizophyllum commune and have found the pattern to be very similar (N. K. Todd \& R. C. Aylmore, unpublished observations). Further investigation of the way in which hyphae respond to various forms of stress or injury, particularly in terms of reversible plugging and patterns of regeneration, will prove invaluable in the understanding of hyphal function and mycelial development.

This work was supported by the Science and Engineering Research Council.

parenthesome cleaves away from the cross-wall [arrowed in (c)]. In the penultimate cell the more heavily stained material of the septal swelling deforms around and over the pore plug (PP). (d) After 30 min the surface of the cross-wall in the empty cell is clear, while pad-like structures have formed on the basal facing surface. (e) Remains of the pore plug embedded in the pad. $(f, g)$. Remnants of parenthesomes (arrowed) $1 \mathrm{~h}$ after injury. Bars, $0.25 \mu \mathrm{m}$. 


\section{REFERENCES}

AYlmore, R. C. (1983). Hyphal fusion in Coriolus versicolor. PhD thesis, University of Exeter.

AYLMORE, R. C. \& TODD, N. K. (1984). A microculture chamber and improved method for combined light and electron microscopy of filamentous fungi. Journal of Microbiological Methods 2, 317-322.

BOURNE, M. (1968). Frontispiece. In Fundamentals of Mycology. Edited by J. H. Burnett. London: Edward Amold.

Bracker, C. E. (1967). Ultrastructure of fungi. Anmual Review of Phytopathology 5, 343-374.

Bracker, C. E. \& Butler, E. E. (1963). The ultrastructure and development of septa in hyphae of Rhizoctonia solani. Mycologia S5, 35-58.

BrAcker, C. E. \& BUTLER, E. E. (1964). Function of the septal pore apparatus in Rhizoctonia soloni during protoplasmic strcaming. Journal of Cell Biology 21, 152-157.

Brenner, D. M. \& Carroll, G. C. (1968). Finestructural correlates of growth in hyphae of Ascodesmis sphaerospora. Journal of Bacteriology 95, 658671.

Brouchart, R. \& Demoulin, V. (1975). Septum ultrastructure of Ostracoderma torrendii. Canadian Journal of Botany 53, 1549-1553.

BuLLER, A. R. H. (1933). Researches on Fungi, vol. S, pp. 130-140. London: Longmans.

Casselton, L. A. \& Casselton, P. J. (1966). Control of fruiting of Coprinus lagopus on certain synthetic media. Transactions of the British Mycological Society 49, 579-581.

Casselton, L. A., Lewis, D. \& Marchant, R. (1971). Septal structure and mating behaviour of common $A$ diploid strains of Coprinus lagopus. Journal of General Microbiology 66, 273-278.

Collinoe, A. J., Miles, E. A. \& Trincl, A. P. J. (1978). Ultrastructure of Penicillium chrysogenum hyphae from colonies and chemostat cultures. Transactions of the British Mycological Saciety 70, 401-408.

Crajg, G. D., Newsam, R. J., Gull, K. \& Wood, D. A. (1977). Subhymenial branching and dolipore septation in Agaricus bisporus. Transactions of the British Mycological Society 69, 337-344.

FurTado, J. S. (1971). The septal pore and other ultrastructural features of the Pyrenomycete Sordaria fimicola. Mycologia 63, 104-113.

GuLL, K. (1978). Form and function of septa in filamentous fungi. In The Filamentous Fungi, vol. 3, pp. 78-93. Edited by J. E. Smith \& D. R. Berry. London: Edward Amold.

Koltin, Y. Flexer, A. S. (1969). Alteration of nuclear distribution in $B$-mutant strains of Schizophyllum commune. Joumal of Cell Science 4, 739749.

Lowry, J. R. \& Sussmun, A. S. (1966). Intrahyphal hyphae in 'clock' mutants of Neurospora. Mycologia 58, $541-548$.

McKeEN, W. E. (1971). Woronin bodies in Erysiphe graminis DC. Canadian Journal of Microbiology 17, $1557-1560$.

MOORE, R. T. MCAlEAR, J. H. (1962). Fine structure of mycota. 7. Observations on septa of ascomycetes and basidiomycetes. American Journal of Botany 49 , 86-100.

MOORE, R. T. \& MARCHANT, R. (1972). Ultrastructural characterisation of the basidiomycete septum of Polyporus biennis. Canadian Journal of Botany 50, 2463-2469.

Reichle, R. E. \& AleXander, J. V. (1965). Multiperforate septations, Woronin bodies and septal plugs in Fusarium. Journal of Cell Biology 24, 489-496.

ReYNOLDs, E. S. (1963). The use of lead citrate at high pH as an electron opaque stain in electron microscopy. Journal of Cell Biology 17, 208-213.

SETLifF, E. C., MACDONALd, W. L. PAtTon, R. F. (1972). Fine structure of the septal pore apparatus in Polyporus tomentosus, Poria latemarginata, and Rhizoctonia solani. Canadian Journal of Botany SO, 25592563.

ShatKIN, A. J. \& TATUM, E. L. (1959). Electron microscopy of Neurospora crassa mycelia. Journal of Biophysical and Biochemical Cytology 6, 423-426.

Trinci, A. P. J. \& Collinge, A. J. (1973). Structure and plugging of septa of wild type and spreading colonial mutants of Neurospora crassa. Archiv für Mikrobiologie 91, 355-364.

WeLLS, K. (1964). The basidia of Exidia nucleata. 1. Ultrastructure. Mycologia 56, 327-341.

WeRGIN, W. P. (1973). Development of Woronin bodies from microbodies in Fusarium oxysporum $\mathrm{f}$. sp. Iycopersici. Protoplasma 76, 249-260.

Wessels, J. G. H. Sietsma, J. H. (1979). Wall structure and growth in Schizophyllum commune. In Fungal Walls and Hyphal Growth, Symposium of the British Mycological Society, pp. 27-48. Edited by J. H. Burnett \& A. P. J. Trinci. Cambridge: Cambridge University Press. 